\title{
Sound production in the Meagre, Argyrosomus regius (Asso 1801): Intraspecific variability associated with size, sex and context
}

\author{
Beatriz P Pereira ${ }^{\text {Corresp., } 1,2}{ }^{2}$, Manuel Vieira ${ }^{3}$, Pedro Pousão-Ferreira ${ }^{4}$, Ana Mendes ${ }^{4}$, Marisa Barata ${ }^{4}$, Paulo J Fonseca \\ 3 , Maria Clara P Amorim ${ }^{2}$ \\ 1 Faculdade de Ciências e Tecnologias, Universidade do Algarve, Faro, Portugal \\ 2 MARE - Marine and Environmental Sciences Centre, Instituto Superior de Psicologia Aplicada, Lisboa, Portugal \\ 3 Departamento de Biologia Animal and cE3c - Centre for Ecology, Evolution and Environmental Changes, Faculdade de Ciências, Universidade de Lisboa, \\ Lisboa, Portugal \\ 4 Instituto Portugês do Mar e da Atmosfera, Olhão, Portugal \\ Corresponding Author: Beatriz P Pereira \\ Email address: beatrizpalinhospereira@gmail.com
}

Background. Many fish taxa produce sound in voluntary and in disturbance contexts but information on the full acoustic repertoire is lacking for most species. Yet, this knowledge is critical to enable monitoring fish populations in nature through acoustic monitoring.

Methods. In this study we characterized the sounds emitted during disturbance and voluntary contexts by juvenile and adult meagre, Argyrosomus regius, in laboratory conditions. Breeding sounds produced by captive adults were also compared with meagre sounds registered in the Tagus estuary (Lisbon, Portugal) from unseen fish during the breeding season.

Results. The present dataset demonstrates for the first time that in this species dominant frequency is inversely related to fish size, and that sounds vary according to sex, context and age. Sounds from captive breeding adults were similar to sounds recorded in the field.

Discussion. Our findings indicate that $A$. regius sound features carry information about size, sex, age and motivation. This variability could potentially be used to identify meagre in the field and to infer about ontogenetic phase (i.e. juveniles vs. adults, and variation with size) and motivation (e.g. spawning). Future studies should confirm sex differences and ascertain the influence of water temperature on acoustic features. 


\title{
Sound production in the Meagre, Argyrosomus regius (Asso 1801): Intraspecific variability associated with size, sex and context
}

\author{
Beatriz P. Pereira ${ }^{1,2}$, Manuel Vieira ${ }^{2,3}$, Pedro Pousão-Ferreira ${ }^{4}$, Ana Candeias-Mendes ${ }^{4}$, Marisa \\ Barata $^{4}$, Paulo J. Fonseca ${ }^{3}$, M. Clara P. Amorim ${ }^{2}$ \\ 1 Faculdade de Ciências e Tecnologia da Universidade do Algarve, e-mail: \\ beatrizpalinhospereira@gmail.com, \\ 2 MARE - Marine and Environmental Sciences Centre, Instituto Superior de Psicologia \\ Aplicada, Lisboa, Portugal \\ 3 Departamento de Biologia Animal and cE3c-Centre for Ecology, Evolution and \\ Environmental Changes, Faculdade de Ciências, Universidade de Lisboa, Lisboa, Portugal, \\ 4 Instituto Português do Mar e da Atmosfera, Av. 5 de Outubro, 8700-305 Olhão, Portugal.
}

\section{ABSTRACT}

Background Many fish taxa produce sound in voluntary and in disturbance contexts but information on the full acoustic repertoire is lacking for most species. Yet, this knowledge is critical to enable monitoring fish populations in nature through acoustic monitoring.

Methods In this study we characterized the sounds emitted during disturbance and voluntary contexts by juvenile and adult meagre, Argyrosomus regius, in laboratory conditions. Breeding sounds produced by captive adults were also compared with meagre sounds registered in the Tagus estuary (Lisbon, Portugal) from unseen fish during the breeding season.

Results The present dataset demonstrates for the first time that in this species dominant frequency is inversely related to fish size, and that sounds vary according to sex, context and age. Sounds from captive breeding adults were similar to sounds recorded in the field.

Discussion Our findings indicate that $A$. regius sound features carry information about size, sex, age and motivation. This variability could potentially be used to identify meagre in the field and to infer about ontogenetic phase (i.e. juveniles vs. adults, and variation with size) and motivation (e.g. spawning). Future studies should confirm sex differences and ascertain the influence of water temperature on acoustic features.

Keywords: Fish acoustic communication; Vocal fish; Disturbance sounds; Breeding sounds; Ontogeny of sound production; Sexual dimorphism; Aquaculture; Field studies; Sciaenidae 


\section{INTRODUCTION}

40

Numerous fish species produce sounds for social communication and when disturbed (Radford et al., 2014), through several sound production mechanisms (Ladich and Fine, 2006; Fine and Parmentier, 2015). Sonic mechanisms are very diverse within this taxon with fish sounds varying between different species and in some cases with size and sex as well (Myrberg et al., 1993; Connaughton et al., 2000; Fine and Parmentier, 2015). Acoustic variability is mainly related to behavioural functions, such as courtship, spawning, agonistic behaviour, competitive feeding, and disturbance (Amorim, 2006; Ladich and Myrberg, 2006). This inter- and intra-specific variability of fish sounds is useful to ascertain the presence, identity and activity of fish in nature (e.g. Borie et al., 2014; Erisman and Rowell, 2017).

Sciaenidae, collectively known as the croakers and drummers, is one of the largest families of vocal fishes (Chao, 1986), known for the conspicuous chorusing behaviour associated with the breeding season (e.g. Luczkovich et al., 1999; Parsons et al., 2013). Representatives of this family produce swimbladder-related sounds by contracting specialized extrinsic sonic muscles against the swimbladder wall (reviewed in Fine and Parmentier, 2015). In most sciaenid species, soundproducing ability is restricted to males (Tower, 1908; Fish and Mowbray, 1970; Hill et al., 1987; Connaughton and Taylor, 1995). However, in some species, such as the black drum (Pogonias cromis), white croaker (Genyonemus lineatus), and meagre (Argyrosomus regius), both males and females possess sonic muscles (Fish and Mowbray, 1970; Takemura et al., 1978; Tellechea et al., 2010, Lagardère and Mariani, 2006).

Passive acoustic monitoring of sciaenids has been used to assess spatial and temporal patterns of fish reproduction by using sounds related with spawning (Fish and Cummings, 1972; Takemura et al., 1978; Saucier and Baltz, 1993; Lagardère and Mariani, 2006; Ueng et al., 2007; Parsons et al., 2009; Montie et al., 2016; Parmentier et al., 2018). However, although several studies on breeding vocalizations have been published for a number of sciaenid species, detailed descriptions of sound parameters and their size-dependent variations are scarce and often restricted to disturbance sounds (Connaughton et al., 2000; Tellechea et al., 2010). For example, Connaughton et al., (2000), found an inverse relation between dominant frequency of disturbance 
68

69

sounds and fish size. These authors showed that for weakfish, Cynoscion regalis, throughout a range of $11 \mathrm{~cm}$ of total length $(25-36 \mathrm{~cm})$ the dominant frequency decreased by $81 \mathrm{~Hz}$ from 560 to $479 \mathrm{~Hz}$. Nevertheless, similarities between breeding (e.g. advertisement) and disturbance sounds, namely in dominant frequency, suggest that the intraspecific variability of disturbance sounds may bear a parallel with that of advertisement sounds. Sex-related differences of vocalizations are also rarely reported since for the majority of the studied sciaenid species, sonic muscles are absent in females. Female and male sounds were described for Micropogonias furnieri, Pogonias cromis, Cynoscion regalis (Tellechea et al., 2010, 2011, 2012), and Argyrosomus japonicus (Ueng et al., 2007). Tellechea et al., (2011) showed that for black drum (Pogonias cromis) only males produced advertisement sounds, while both sexes emitted sounds when disturbed. Ueng et al., (2007) observed that in Japanese croaker (Argyrosomus japonicus) the advertisement sounds of the male and female differ; females generated significantly more pulses per call, and their sounds had a longer call duration, a shorter pulse period, and a lower dominant frequency than those of males.

The meagre, Argyrosomus regius (Asso, 1801), is a vocal sciaenid widely distributed along the Atlantic coast of Europe and Africa, and in the Mediterranean (Chao, 1986). It is a species with a high commercial value, being farmed in several countries since the 1990s (Monfort, 2010; FAO, 2011). While advertisement sounds produced during spawning aggregations and the sexual dimorphism of sonic muscles have been characterised in this species (Lagardère and Mariani, 2006; Vieira et al., 2019), there is still a lack of information on their wider vocal repertoire, including whether females make sounds, and the variability of sound production associated with social context (disturbance vs. reproductive) or ontogenetic phase (vocal repertoire of juvenile vs. adult, and variation with size). Such knowledge could be useful to identify juveniles and adult meagre in the field, e.g. allowing recognition of young fish shoals and reproduction areas.

The present study aimed to describe disturbance and voluntary sounds produced by juvenile and adult meagre to examine intraspecific variability of the acoustic signals associated with context, size and sex. In addition, we aimed to compare sounds registered in an aquaculture setup with field recordings. Our data suggests that it might be possible to monitor the meagre in the field using passive acoustics, and that intraspecific variability in the acoustic signals renders the opportunity to discriminate ontogenetic groups and reproduction stages. 
98

99

100

101

102

103

104

105

106

107

108

109

110

111

112

113

114

115

116

117

118

119

120

121

122

123

124

125

126

127

128

129

130

131

\section{MATERIALS AND METHODS}

Captive fish

Sound recordings were obtained from a group of adult breeders and juvenile meagre, $A$. regius, reared at the aquaculture facilities of Instituto Português do Mar e da Atmosfera - Estação Piloto de Piscicultura de Olhão (IPMA - EPPO), Portugal $\left(37^{\circ} 02^{\prime} \mathrm{N}, 7^{\circ} 49^{\prime} \mathrm{W}\right)$. IPMA is an institution certified to perform experimental work with animals. It has an authorization according to EU legislation for EPPO to breed, use and supply aquatic animals for scientific experimental work provided by DGAV - the Portuguese National Authority for Animal Health - (DGAV reference 0421/000/000/2018). All fish were housed in aquaculture tanks with continuous filtered water supply, under controlled water temperature (ranging from $14^{\circ} \mathrm{C}$ to $23^{\circ} \mathrm{C}$, measured once a day), controlled $\mathrm{pH}(8 \pm 0.4)$, salinity $(37 \pm 1.0 \mathrm{psu})$ and oxygen level close to saturation $(80 \pm 7.6 \%)$.

Photoperiod conditions were set to mimic natural regimes (10L/14D hours, with low light intensity at dawn and dusk). Juveniles' photoperiod was larger; these individuals were provided with natural sunrise light, and artificial light prolonged the photoperiod until 23:00 all year round.

The studied adult breeders $(n=10) 6$ and 9 years old, were reared in indoor concrete parallelepipedic tanks ( $3 \mathrm{~m}^{2}$ area, $1.2 \mathrm{~m}$ deep), and were the offspring of wild individuals hosted in the aquaculture facilities. Adult meagre exhibited an average total length (TL) of $87 \mathrm{~cm}$ ranging 69-102 cm, and a 4:6 (M:F) sex ratio. These individuals were fed inert semi-moist feeds several times a day. Subject juveniles were reared in two indoor 9000L fiberglass circular tanks (3 m diameter, $1.6 \mathrm{~m}$ deep). One tank housed 1 and 2 year-old juveniles $(\mathrm{n}=208)$ ranging in TL from approximately 30 to $50 \mathrm{~cm}$, respectively. The other tank reared 2.5 month-old juveniles $(\mathrm{n}=4000)$, with an average TL of ca. $9 \mathrm{~cm}$. Note that meagre attains maturity at ca. $86 \mathrm{~cm}$ TL but only shows signs of spawning activity at ca. $100 \mathrm{~cm}$ TL in the wild (Prista et al., 2014) while in aquaculture conditions it can mature at shorter lengths (length at 50\% maturity at ca. $50 \mathrm{~cm}$ and around 3 years of age; Gil et al., 2013). The studied non-breeder fish are thus juveniles due to their size and age ( TL $<50 \mathrm{~cm}$; age $\leq 2$ years) and because they never showed any signs of sexual activity.

Recording of vocalizations in captive fish

Peer] reviewing PDF | (2019:05:37653:2:1:CHECK 16 Dec 2019) 


\section{Ontogenetic and sex variation of disturbance sounds}

133

134

135

136

137

138

139

140

141

142

143

144

145

146

147

148

149

150

151

152

153

154

155

156

157

158

159

160

161

162

Vocalizations of juveniles with different size were individually recorded at ca. $20^{\circ} \mathrm{C}$ water temperature in May 2018. Two 200L plastic circular containers were filled with water from the rearing tanks under continuous aeration. A group of 20 juveniles with an average TL of $35 \mathrm{~cm}$, ranging from $30-50 \mathrm{~cm}$ in TL, was transferred (10 at a time) with a hand-net to one of the 200L containers. A single individual was then rapidly measured for total length and weight and transferred with a plastic sleeve bag to the second 200L container where recordings were carried out (Fig. 1). This fish was kept inside the sleeve and sometimes stimulated by pressing the caudal peduncle while disturbance sounds were recorded for 3 min with a High Tech 94 SSQ hydrophone (High Tech Inc., Gulfport, MS, USA; sensitivity of $-165 \mathrm{~dB}$ re $1 \mathrm{~V} / \mu \mathrm{Pa}$, frequency response up to $6 \mathrm{kHz}$ within $\pm 1 \mathrm{~dB}$ ), placed at approximately $10 \mathrm{~cm}$ from the fish's abdomen, and connected to a Tascam DR-40 Portable Digital Recorder (44.1 kHz sampling rate, 16 bit; TEAC, Europe Gmbh).

To check for sound production in smaller fish, similar recordings of disturbance sounds were conducted with a group of 10 randomly selected 2.5 month-old juveniles with an average TL of ca. $9 \mathrm{~cm}$. The recording protocol was similar to the one above, except that fish were transferred to a $10 \mathrm{~L}$ glass beaker with water from the original tank also at approximately $20^{\circ} \mathrm{C}$. As before, disturbance sounds were recorded individually. Furthermore, one individual with $10 \mathrm{~cm}$ TL was transported to the laboratory facilities at University of Algarve, for dissection to inspect soundproducing muscles. For this purpose, the fish was euthanized with an overdose of MS222 (tricaine methane sulfonate solution buffered with sodium bicarbonate to a neutral $\mathrm{pH}$; Pharmaq, Norway).

A similar experimental design was carried out in July 2018 for the adult breeders (see above). However, prior to sampling, the water level in the indoor tank was lowered by $1 \mathrm{~m}$ and all fish (fasted for $24 \mathrm{~h}$ ) were anaesthetized with $40 \mathrm{ppm}$ of 2-phenoxyethanol (2-PE) to reduce stress and prevent fish from jumping and harming themselves while being captured. Following the juveniles' recordings protocol, two 200L containers filled with aerated seawater from the rearing tanks and without anaesthetic, were used. Water temperature was the same as in juveniles $\left(\sim 20^{\circ} \mathrm{C}\right)$ to rule out differences in the sounds due to temperature-dependent effects. After $20 \mathrm{~min}$, anaesthetized individuals were safely captured with a plastic sleeve bag and transferred in groups of 3 to the first 200L container, where fish were allowed to recover for approximately 15 min after 
163 which they showed no signs of anaesthesia. Then, each breeder was individually identified by chip 164 reading and transferred with a sleeve to the second 200L container where recordings were carried 165 out (Fig. 1). Barata et al., (2016) tested the efficiency of 2-phenoxyethanol (2-PE) in juveniles of 166 this species at IPMA, based on the stages of anaesthesia described by Iwama et al., (1989): total 167 loss of equilibrium (Stage AI), loss of gross body movements (Stage AII), and cessation or 168 imperceptible opercular movements (Stage AIII). According to the study, after being exposed for

$16910 \mathrm{~min}$ to $100 \mathrm{mg} / \mathrm{L}$ of 2-PE, meagre juveniles lost equilibrium (AI) but continued to exhibit 170 locomotion and opercular movements and took approximately 4 min do recover. Hence, we are 171 confident that adult breeders were allowed enough time to recover. Biometric samplings were 172 conducted a few days later, with breeders fasted for $48 \mathrm{~h}$ being submitted to a higher dose of 173 anaesthetic (200 ppm). In addition to total length and weight measurements, sex determination of 174 individuals was attempted. Since external sexual dimorphism is not present in meagre, sex

175 identification was carried out overwater by carefully turning the fish upside down and gently 176 pressing the abdomen to check if sperm was released through the genital papilla. In the case of 177 sperm release, individuals were considered males. Otherwise, a flexible polystyrene catheter was 178 inserted in the genital papilla to extract gonadal tissue and identify the fish as female. However, 179 except for two females, gonadal tissue extraction was not succeeded, and female sex was attributed to individuals that in various samples over the previous 3 years never released milt when their abdomen was pressed.

182

183

184

185

186

187

Ontogenetic variation of sounds made during voluntary contexts

On May 2018, recordings of juvenile individuals (on the tank with individuals ranging from ca. 30-50 cm; see above), were conducted for $2 \mathrm{~h}$ using a Tascam DR-40 Portable Digital Recorder connected to a High Tech 94 SSQ hydrophone vertically positioned at the centre of the tank at approximately $30 \mathrm{~cm}$ from the bottom. Water temperature in the tank was $19.8^{\circ} \mathrm{C}$. Sounds of adult individuals $(\mathrm{n}=10$; see above) with an average total length (TL) of $87 \mathrm{~cm}$ ranging 69-102 cm, and a 4:6 (M:F) sex ratio, were recorded during the spawning season, on July 2018. For this purpose, a High Tech 94 SSQ hydrophone was vertically positioned at the centre of the tank at approximately $30 \mathrm{~cm}$ from the bottom and connected to a stand-alone 16 channel datalogger (LGR - 5325, Measurement Computing Corp, Norton Ma USA; $12 \mathrm{kHz}$ sampling rate 
19316 bit, $\pm 1 \mathrm{~V}$ range). Water temperature in the tank was $21.3^{\circ} \mathrm{C}$. Note that the identity of the calling

194 fish was not known in these recordings, both in juvenile and in adult fish.

196 Vocalizations recordings in the field

197

198

199

200

201

202

203

204

205

206

207

208

209

210

211

212

213

214

215

216

217

218

219

220

221

222

223

224

Five-day round-the-clock recordings of breeding sounds were obtained in May and June 2018, in the Tagus estuary (Air Force base 6, Montijo, Portugal; 38 $42^{\prime} \mathrm{N}, 8^{\circ} 58^{\prime} \mathrm{W}$ ). Sound recordings were obtained from wild adult breeders with unknow size, sex ratio and group size. For this purpose, a hydrophone was anchored at about $20 \mathrm{~cm}$ from the bottom to a stainless-steel holder projecting from a concrete base where the cable was attached to minimise current-induced hydrodynamic noise. The signal from the hydrophone was recorded by a 16 channel stand-alone data logger. Diurnal temperature variation was highly influenced by the tide, with a mean of $20.2^{\circ} \mathrm{C}$ and a range between $17.1-21.8^{\circ} \mathrm{C}$. Water depth varied approximately between 3-6 $\mathrm{m}$, depending on tide.

Sound Analysis

Sounds were edited with Adobe Audition 3.0 (Adobe Systems Inc., CA, USA) and analysed with Raven 1.5 (The Cornell Lab of Ornithology, NY, Ithaca). Only the sounds with a good signalto-noise ratio were used in the analyses. The following temporal parameters were measured from disturbance and voluntary sounds (Fig. 2): sound duration (ms), as the time from the onset of the first pulse to the offset of the last pulse; number of pulses; pulse period (ms), as the average time between the peaks of two consecutive pulses in a sound. Pulse period was obtained by dividing the duration of the sound by the number of pulses minus 1. The measured spectral parameters were: peak (or dominant) frequency $(\mathrm{Hz})$, the frequency with the highest energy in the sound; $1^{\text {st }}$ and $3^{\text {rd }}$ Quartile Frequencies (Q1 and Q3 frequency, Hz), the frequencies that divide the selection into two frequency intervals containing $25 \%$ and $75 \%$ of the energy in the selection. Temporal parameters were measured from oscillograms while frequency parameters were measured from power spectra (6 kHz, FFT size 1024 points, Hamming window, 50\% time overlap) with Raven 1.5 custom tools.

To examine ontogenetic and sex variation of disturbance sounds a total of 600 sounds were randomly selected and manually analysed (20 sounds per individual for each of the 20 juveniles 
225

226

227

228

229

230

231

232

233

234

235

236

237

238

239

240

241

242

243

244

245

246

247

252

253

254

255

256

and 10 adults recorded).

To study ontogenetic variation of sounds made during voluntary context in captivity, a total of 100 sounds (50 for juveniles and 50 for adults) were analysed. The analysed juvenile sounds were produced in May 15 around 14h while the sounds analysed for adults were produced in July 7 between $18 \mathrm{~h}$ and $23 \mathrm{~h}$. In the case of adults, the chosen time window corresponds to the diel vocal activity period exhibited by this species (Vieira et al., 2019). The selected sampling day was the one in which water temperature was the most similar to disturbance recordings.

To compare breeding sounds produced in captivity with those produced in the field an additional 20 voluntary sounds registered in captivity during the spawning season were considered, to increase sample size $(n=70)$. Fifty sounds emitted during the spawning season in the Tagus estuary were analysed. These sounds were selected from field recordings in periods during which water temperature was similar $\left(\sim 20^{\circ} \mathrm{C}\right)$ to the one registered in captivity $\left(\sim 21^{\circ} \mathrm{C}\right)$ to minimise differences due to temperature. When meagre sounds were produced in dense choruses individual sounds could not be distinguished in field recordings. Hence, only individual sound emissions that occurred before and after the main chorus were analysed.

\section{Statistical Analyss}

Statistical analysis was conducted using the software Statistica (version 13, TIBCO Software inc, Palo Alto, CA, USA).

To assess the influence of fish total length (TL) on all acoustic variables of disturbance sounds, Pearson correlation tests were used. Data in these tests considered mean values per fish (n $=30,20$ sounds per fish, total of 600 sounds) for each acoustic variable. Because frequency parameters were inter-correlated $(r=0.57-0.73, p<0.05)$ the effects of context, ontogenetic phase and sex were only investigated for peak frequency, the parameter that showed the highest correlation coefficient with fish TL.

To assess differences in sound features between contexts (disturbance and voluntary) and ontogenetic groups (juveniles and adults), two-way ANOVAs were conducted considering 50 sounds per context for each ontogenetic group/context. In these analyses, data concerning disturbance sounds were restricted to 50 randomly selected sounds from the whole data set to avoid large imbalances between factor level sample sizes. To meet the ANOVA assumptions the 
257 reciprocal transformation $\left(x^{\prime}=1 / x\right)$ was used for sound duration and number of pulses and the 258 quadratic $\left(\mathrm{x}^{\prime}=\mathrm{x}^{2}\right)$ for pulse period. Post-hoc Tukey HSD tests were used to assess pairwise 259 differences. Non-parametric two-way ANOVA was carried out for peak frequency, following 260 (Marôco, 2018), since homogeneity of variances was not met even after performing the usual data 261 transformations. To further explore fine differences in disturbance and voluntary sounds in 262 juveniles and adults, plots were made between the different acoustic parameters and number of 263 pulses using all analysed sounds. Differences in slopes in the relation between sound duration and 264 number of pulses between voluntary and disturbance sounds were examined with an ANCOVA 265 (homogeneity-of-slope model). The reciprocal transformation $\left(x^{\prime}=1 / x\right)$ was used for sound 266 duration to stabilize the error variances.

To examine sex-related differences of disturbance call characteristics, an ANCOVA was 268 performed using sex as a factor and TL as the covariate. As TL had a non-significant effect, it was removed from the analysis. Male and female sound characteristics were then compared with Student's t-tests. The data used in this analysis were mean values of 20 sounds for each of the 4 males and 6 females. Data met the assumptions of normality and homogeneity of variances.

272

Voluntary sounds recorded in captivity (total of 70 sounds) were compared with meagre

273

274

275

276 277

278

279

280

281

282

283

284

285

286

\section{RESULTS}

\section{Ontogenetic and context variation of sounds}

No disturbance sounds were registered from the small juveniles of ca. $9 \mathrm{~cm}$. Dissection of one individual showed that it was a male (testes were visible) but sonic muscles were not visible (Fig. 3). Fig. 3 depicts the swimbladder, consisting of a single chamber, located between the viscera and the vertebral column. Disturbance and voluntary sounds were registered from the remaining studied fish $(\mathrm{TL}>30 \mathrm{~cm})$. 
All acoustic features of disturbance sounds were significantly correlated with total length

288

289

290

291

292

293

294

295

296

297

298

299

300

301

302

303

304

305

306

307

308

309

310

311

312

313

314

315

316

317 with the exception of Q1 frequency (Table 1, Fig. 4). Sound duration and number of pulses increased with fish size while pulse period, peak frequency and Q3 frequency decreased. On average, across a range of $71 \mathrm{~cm}$ in total length $(31-102 \mathrm{~cm})$ sound duration increased $9 \mathrm{~ms}$ from 126 to $135 \mathrm{~ms}$, the number of pulses increased by 3 from 12 to 15, pulse period decreased by $2 \mathrm{~ms}$ from $11 \mathrm{~ms}$ to $9 \mathrm{~ms}$ and peak frequency decreased by $79 \mathrm{~Hz}$ from $340 \mathrm{~Hz}$ to $261 \mathrm{~Hz}$.

The context of sound production had a significant effect on all sound features (Table 2 and 3; Fig. 5). Sounds emitted in a voluntary context were longer, presented a higher number of pulses, longer pulse periods, and higher peak frequency than disturbance sounds in both ontogenetic groups. There was a significant effect of the ontogenetic phase on sound duration and number of pulses which increased from juveniles to adults. However, post-hoc Tukey HSD tests showed no significant differences in sound duration between juveniles and adults either for disturbance $(p=$ $0.14)$ or for voluntary sounds $(p=0.15)$. The number of pulses increased in adults both for disturbance sounds (Tukey HSD test, $p<0.01$ ) and for voluntary sounds (Tukey HSD test, $p<$ 0.05 )

\section{$0.05)$}

3 than voluntary sounds, with $16 \pm 3$ (mean \pm SD) pulses in adult males, $15 \pm 6$ pulses in adult females and $11 \pm 4$ pulses in juveniles (Fig. 2, Table 2). The pulses of disturbance sounds were typically formed by pulses with a single major cycle (Fig. 1). The voluntary sounds recorded in captivity were pulse trains with $39 \pm 15$ pulses in adults and $16 \pm 6$ pulses in juveniles. The juvenile voluntary sounds were also typically formed by pulses with a single major cycle (Fig. 1), while the adult sounds (either in captivity or in the field) were typically formed by pulses with distinguishable multiple cycles. Additionally, the sounds pulses recorded in the field appear to attenuate more rapidly than in the tank suggesting some reflections or tank resonance.

Plotting the several acoustic parameters against the number of pulses of sounds further illustrates the aforementioned differences between disturbance and voluntary sounds, in both juveniles and adults. Sound duration increased linearly with the number of pulses per sound both in voluntary and disturbance contexts for both ontogenetic groups, but in voluntary sounds the number of pulses increased more steeply than in disturbance sounds (ANCOVA; juveniles $F_{1,418}$ $=56,11, p<0.001$; adults $F_{1,190}=62.26, p<0.001$; Fig. 6A,B). Sounds produced by adults were also longer and included a higher number of pulses than the ones produced by juveniles. In contrast 
318 to juveniles, the adults pulse number range was clearly wider in voluntary than in disturbance

319 contexts (Fig. 6A,B; Table 3). Pulse period was longer and peak frequency higher in voluntary

320 sounds of both groups (Fig. 6C-F). Pulse period was more irregular in disturbance than in voluntary

321 sounds, especially in sounds with less than 5 pulses. The analysed voluntary sounds always

322 presented more than 5 pulses. In both ontogenetic groups, peak frequencies of disturbance and

323 voluntary sounds varied greatly with the number of pulses, showing no clear pattern (Fig. 6E,F).

324

325

326

327

328

329

330

331

332

333

334

335

336

337

338

339

340

341

342

343

344

345

346

347

348

349

350

351

\section{4}

345

Sex variation of disturbance sounds

Sex-related differences of disturbance sounds characteristics were analysed for 4 males and 6 females (20 sounds per fish) (Fig. 7, Table 3). Disturbance sounds produced by males and females differed significantly in all acoustic parameters, with the exception of the number of pulses $(t=0.23 ; p=0.83 ;$ d.f. $=8)$. Male sounds were longer than those emitted by females $(t=-2.35 ; p$ $<0.05$; d.f. $=8)$, had a longer pulse period $(t=-2.99 ; p<0.05$; d.f. $=8)$ and a higher peak frequency $(t=-2.72 ; p<0.05 ;$ d.f. $=8)$.

\section{Field vs. Captivity}

The sounds registered in the field and in captivity consisted of sequences of pulses (not analysed) and grunts of variable durations and number of pulses. The field grunts showed similar sound duration $(t=-0.75 ; p<0.001$; d.f. $=118)$, number of pulses $(t=0.48 ; p<0.001 ;$ d.f. $=118)$ and peak frequency $(t=-0.90 ; p<0.001$; d.f. $=118)$ to those emitted in captivity but differed in pulse period (ANCOVA; context $F_{1,117}=61,53, p<0.001$; water temperature $F_{1,117}=30.20, p<$ 0.001; Fig. 8, Table 3).

\section{DISCUSSION}

Our knowledge on the detailed acoustic repertoire and variability of the sounds is lacking in most vocal fish species. The present dataset demonstrates for the first time that $A$. regius sounds varied with fish size, ontogenetic phase, sex, and context (disturbance and voluntary). Sound duration and number of pulses of disturbance sounds increased while pulse period, peak frequency and Q3 frequency decreased with increasing fish body size. Sexual dimorphism was significantly 
352 present in sound duration, pulse period and peak frequency of disturbance sounds, with males

353 exhibiting higher values. Sounds produced in voluntary context showed significant differences

354 between juveniles and adults, with adults exhibiting longer sounds with a higher number of pulses.

355 Additionally, sounds produced by both adults and juveniles showed significant differences

356 between disturbance and voluntary contexts, with disturbance sounds being of shorter duration,

357 including fewer pulses, and having a shorter pulse period and a lower peak frequency than

358 voluntary sounds. Though grunts with less than 5 pulses are produced by this species in voluntary

359 contexts (Vieira et al., 2019), in this study, these short sounds were not registered, likely because

360 the sounds produced were connected with breeding in which sounds tend to be of long duration,

361 or due to the short sampling effort. Finally, advertisement sounds recorded in Tagus estuary were

362 similar to the ones registered in captivity although they differed in the pulse period, possibly

363 associated with disparities in the environment and fish, such as the existence of higher temperature

364 fluctuations in the field (Ladich, 2018) and different sizes or group composition of the sound

365 emitters. Sounds registered in the field were from unseen fish which were possibly larger than captive ones and also likely calling in larger aggregations.

367

368

369

\section{Ontogenetic and context variation of sounds}

370

In this study, sounds emitted in two types of contexts were characterised for juveniles and

adults $A$. regius: voluntary and disturbance. It is well-known that sciaenids are vocal species that produce sounds in courtship and disturbance contexts (Connaughton et al., 2000, 2002a; Lin et al., 2007; Tellechea et al., 2017). Though advertisement sounds produced during spawning aggregations have been characterised for A. regius (Lagardère and Mariani, 2006), disturbance sounds and their relation with size have never been studied for this species. As mentioned before, in $A$. regius (like in other sciaenids) sound production is elicited by the contraction of welldeveloped extrinsic sonic muscles that surround the swimbladder (Tavolga, 1964; Ladich and Fine, 2006). The waveform of both the disturbance and voluntary sounds of $A$. regius consisted of similar rapidly-damped pulses, suggesting that both sounds are produced by the same mechanism. Plus, contractions of the sonic muscles could be felt when handling the fish.

Disturbance sounds produced when juveniles $(31-51 \mathrm{~cm})$ and adults $(69-102 \mathrm{~cm})$ were 
383 parameters such as pulse duration and peak frequency are determined by sonic muscle activity, 384 rather than the resonant frequency of the swimbladder, which is thought to be strongly correlated 385 with fish size. The increase of sound duration and decrease of peak and Q3 frequencies observed 386 in this study support Connaughton and colleague's conclusion of a forced rather than a resonant 387 response. Therefore, longer muscles, presumably with longer fibres, take longer to complete a 388 twitch in larger fish resulting in longer pulses (presumably longer sounds) and also in lower sound 389 frequencies. These results are in line with other studies on species belonging to the family 390 Sciaenidae that demonstrated the same relation between these parameters and body size 391 (Connaughton et al., 2000; Tellechea et al., 2010). However, whether A. regius is able to evaluate 392 these differences to extract information still needs to be tested.

Two-way ANOVAs considering 50 sounds per ontogenetic phase and context showed that,

394 when considering both disturbance and voluntary sounds, there was an increase in duration and 395 number of pulses from juveniles to adults, but no variation was observed for the pulse period or 396 peak frequency. These results were not surprising since the acoustic apparatus has been shown to 397 increase throughout ontogeny in other sciaenids (Hill et al., 1987), likely increasing the ability to 398 produce longer sounds with more pulses. Additionally, voluntary sounds produced by adults may 399 be connected to breeding as sounds were recorded in the beginning of July, concurrent with the spawning period that characterizes this species (Costa et al., 2008). As such, it is expected that the sounds produced by mature, ready to spawn meagre are longer and include more pulses than the ones produced by immature juveniles. In contrast to what was observed for disturbance sounds, when considering sounds from both contexts, there was no decrease in peak frequency with fish size. This could be due to the high variability in this parameter arising from sounds presenting many harmonics with similar relative amplitude (Fig. 2).

The most marked variation in sound features was observed for context of sound production.

407 For both ontogenetic groups, significant differences between the two contexts were found for all 408 parameters of sounds, with disturbance sounds being of shorter duration, including fewer pulses, and having a shorter pulse period and a lower peak frequency than voluntary sounds. In line with 410 the observations made in this study, differences have been found between disturbance and 411 voluntary sounds for other species in which agonistic sounds are brief and broadband (harsh) 412 whereas sounds uttered in other contexts (submission, courtship) are frequently of longer duration 413 and occasionally tonal (Crawford et al., 1986; Ladich and Tadler, 1988; Ladich et al., 1992; 
414 McKibben and Bass, 2001). For example, the male midshipman (Porichthys notatus) produce tonal 415 hums of long duration to attract pregnant females to the nest and short broadband grunts to defend 416 the nest from potential intruders (McKibben and Bass, 2001). Physiologically, these differences 417 are mainly related with differences in the contraction rate of sonic muscles (Fine et al., 2001). 418 Furthermore, they are probably associated with differences in production rate and function of the 419 two call types. According to Lagardère and Mariani (2006), advertisement sounds of the meagre 420 are mainly characterised by long grunts produced at a constant high rate for several tens of minutes. 421 This implies higher costs of advertisement sounds, not only physiologically and metabolically (i.e. 422 higher sonic muscle contraction rates for longer periods; Fine et al., 2001), but also at an ecological 423 level (e.g., attraction of predators). Consequently, it is likely that longer sounds and higher calling 424 rates are used as direct signals of male quality and motivation for mate choice by females.

Sex variation of disturbance sounds

The present dataset demonstrates for the first time that female meagre emit sounds and that 429 their sounds differ from those of males. Both male and female A. regius emitted pulse trains (grunts) when handled. In most sciaenid species (e.g., Cynoscion regalis and Sciaenops ocellatus) only males possess sonic muscles (Tower, 1908; Fish and Mowbray, 1970; Hill et al., 1987). There are relatively few species in which these muscles are present in both sexes (e.g., Micropogonias undulatus, Micropogonias furnieri, Pogonias cromis, Argyrosomus regius, Cynoscion guatucupa, and Argyrosomus japonicus) (Hill et al., 1987; Lagardère and Mariani, 2006; Ueng et al., 2007; Tellechea et al., 2010, 2011, 2012). Sexual dimorphism of the sound-producing apparatus has been observed in three species of the genus Argyrosomus, including the meagre (Takemura et al., 1978; Lagardère and Mariani, 2006; Ueng et al., 2007). Until now no information was available on the ability of females of these species to produce sound.

In this study, with the exception of the number of pulses, sexual dimorphism was significantly present in all of the studied acoustic parameters of sounds (sound duration, pulse period and peak frequency), with males exhibiting higher values. Hence, besides carrying information related to the size, dominant frequency and call duration could also be signals passing on information on the sex of the producer. There is a strong correlation between size and sex, with males usually having better developed sonic muscles associated to their larger size (Allen, 1972;

445 Ladich and Fine, 2006). Male and female meagre used in this study did not differ significantly in 
446 total length. Females had a tendency to be larger (mean TL of $87 \mathrm{~cm}$ for females $v s .82 \mathrm{~cm}$ for 447 males) which could explain the higher peak frequency of their sounds. A similar result was 448 observed for the closely-related species Argyrosomus japonicus (Ueng et al., 2007). However, as 449 in this experiment female gonadal tissue extraction was only succeeded for two individuals, female 450 sex may have been incorrectly attribute to a non-sperm-producing male. Also sounds from more 451 individuals should be recorded as the sample size was very small in the present study and results 452 should be considered with caution.

453 Sound production by females could be associated with agonistic interactions as in other 454 genus (e.g. Cichlasoma centrarchus, Schleinzer, 1992; Trichopsis vittata, Ladich, 2007). Whether 455 females vocally take part in spawning is still unknown. Future experiments, in which 456 advertisement sounds produced by A. regius are recorded for a single-sex group during the 457 spawning season should provide answers to this question.

458

459

460

461

462

463

464

465

466

467

468

469

470

471

472

473

474

475

476

Field vs. Captivity

Advertisement grunts recorded in the Tagus estuary were similar to the ones recorded in captivity but differed significantly from those of captive individuals in pulse period. This may be explained by the diurnal temperature fluctuations observed in the field (ranging from 18 to $23^{\circ} \mathrm{C}$ ), which are highly influenced by tides, in contrast to more constant temperatures in captivity. Sound parameters associated with muscle contraction have been shown to change with temperature (Connaughton et al., 2000, 2002b; Ladich, 2018). Moreover, water temperature appears to be the most important factor determining meagre migrations and reproduction (FAO, 2005 - 2011b). Additionally, the shorter pulse period of the sounds produced by captive individuals could be associated with different levels of motivation. While in the field the analysed sounds occurred outside the main chorus, in captivity individual sounds could be easily distinguished due to the smaller number of individuals. As such, it is likely that the latter were produced closer to spawning than the sounds analysed for wild fish.

\section{Concluding remarks}


The variation in sounds documented in the present study indicates that $A$. regius

478

480

481

482

483

484

485

486

487

488

489

490

491

492

493

494

495

496

497

498

499

500

501

502

503

504

505

506

507

508

509

510

511

512

513 vocalizations have the potential to carry information about species, size, sex, ontogeny, motivation, and other factors that may play a role in both voluntary and disturbance contexts. This variation in sound parameters may be valuable to fisheries biologists monitor natural populations of meagre with passive acoustic monitoring. For example, these differences could be used to detect meagre in the field and further attempt to ascertain ontogenetic phase (Sprague and Luczkovich, 2001), or to chart temporal and spatial patterns of meagre reproduction through the detection of spawning sounds as in other sciaenids (Connaughton and Taylor, 1995; Luczkovich et al., 1999, 2008; Rowell et al., 2017). Further research to confirm differences between sex and ascertain the influence of other sources of variability such as water temperature could be valuable for such passive acoustic monitoring.

Acknowledgements

We would also like to thank Teresa Modesto for her contributions to this project. This study was funded by Fundação para a Ciência e a Tecnologia, Portugal (project PTDC/BIA-BMA/30517/2017 and project PTDC/BIABMA/29662/2017; SFRH/BD/115562/2016 to M.V.; and the strategic projects UID/MAR/04292/2019 granted to MARE and UID/BIA/00329/2019 granted to CE3C).

\section{REFERENCES}

Allen, G.R. (1972). The Anemonefishes. Their Classification and Biology. T.F.H. Publications, Neptune City, NJ, USA (2nd ed.)

Amorim, M. C. P. (2006). Diversity of sound production in fish. Communication in fishes, 1, 71104.

Barata, M., Soares, F., Aragão, C., Almeida, A. C., Pousão-Ferreira, P., and Ribeiro, L. (2016). Efficiency of 2-phenoxyethanol and Clove Oil for Reducing Handling Stress in Reared Meagre, Argyrosomus regius (Pisces: Sciaenidae). Journal of the World Aquaculture Society, 47(1), 82-92.

Borie, A., Mok, H. K., Chao, N. L., and Fine, M. L. (2014). Spatiotemporal variability and sound characterization in Silver Croaker Plagioscion squamosissimus (Sciaenidae) in the Central Amazon. PloS one, 9(8), e99326.

Chao, L. N. (1986). A synopsis on zoogeography of the Sciaenidae. Indo-Pacific fish biology: proceedings of the second international conference of Indo-Pacific fishes. T. Uyeno, R. Arai, T. Taniuuchi, and K. Masuura (eds.). Ichthyological Society of Japan, Tokyo, 570 - 589

Connaughton, M. A., Fine, M. L., and Taylor, M. H. (2002b). Use of sound for localisation of 
514

515

516

517

518

519

520

521

522

523

524

525

526

527

528

529

530

531

532

533

534

535

536

537

538

539

540

541

542

543

544

545

546

547

548

549

550

551

552

spawning weakfish in delaware bay (usa) and effects of fish size, temperature and season on sound parameters. Bioacoustics, 12(2-3), 294-296.

Connaughton, M. A., Lunn, M. L., Fine, M. L., \& Tayor, M. H. (2002a). Characterization of sounds and their use in two sciaenid species: weakfish and Atlantic croaker. Listening to Fish, Passive Acoustic Applications in Marine Fisheries, 15 -19

Connaughton, M. A., Taylor, M. H., and Fine, M. L. (2000). Effects of fish size and temperature on weakfish disturbance calls: Implications for the mechanism of sound generation. Journal of Experimental Biology, 1512(2000), 1503-1512

Connaughton, M. A., and Taylor, M. H. (1995). Seasonal and daily cycles in sound production associated with spawning in the weakfish, Cynoscion regalis. Environmental Biology of Fishes, 42(3), 233-240.

Costa, M. J., Cabral, H., Costa, J. L., Prista, N., Lopes, J. C., (2008). Corvina-legítima Argyrosomus regius - Dados biológicos para a gestão e produção aquícola de um recurso". Final Report (Project Ref: DGPA-MARE: 22-05-01-FDR-00036), Centro de Oceanografia, Faculdade de Ciências da Universidade de Lisboa, Lisboa, Portugal.

Crawford, J. D., Hagedorn, M., \& Hopkins, C. D. (1986). Acoustic communication in an electric fish, Pollimyrus isidori (Mormyridae). Journal of Comparative Physiology A, 159(3), 297310.

Erisman, B. E., and Rowell, T. J. (2017). A sound worth saving: acoustic characteristics of a massive fish spawning aggregation. Biology letters, 13(12), 20170656.

FAOC (2011) FAO Fisheries Department, Fishery Information, Data and Statistics Unit. FISHSTAT Plus: Universal software for fi shery statistical time series. Version 2.3. 2000. Data sets: Aquaculture production: quantities and values 1950- 2009; Capture production 1950-2009.

FAO (C (2005-2011b), Cultured Aquatic Species Information Programme. Argyroso- mus regius. Cultured Aquatic Species Information Programme. Text by Stipa, P; Angelini, M In: FAO Fisheries and Aquaculture Department [online]. Rome. Updated 10 February 2005.

Fine, M. L., Malloy, K. L., King, C., Mitchell, S. L., and Cameron, T. M. (2001). Movement and sound generation by the toadfish swimbladder. Journal of comparative Physiology A, 187(5), 371-379.

Fine, M. L., and Parmentier, E. (2015). Mechanisms of Fish Sound Production. Sound Communication in Fishes, 4, 77-126.

Fish, J. F., \& Cummings, W. C. (1972). A 50-dB increase in sustained ambient noise from fish (Cynoscion xanthulus). The Journal of the Acoustical Society of America, 52(4B), 1266-1270.

Fish, M. P., and Mowbray, W. H. (1970). Sounds of Western North Atlantic Fishes : A Reference File of Biological Underwater Sounds. Rhode Island Univ Kingston Narragansett Marine Lab.

Hill, G. L., Fine, M. L., and Musick, J. A. (1987). Ontogeny of the sexually dimorphic sonic muscle in three sciaenid species. Copeia, 708-713. 
553 Iwama, G. K., McGeer, J. C., and Pawluk, M. P. (1989). The effects of five fish anaesthetics on 554 acid-base balance, hematocrit, blood gases, cortisol, and adrenaline in rainbow trout. 555 Canadian Journal of Zoology, 67(8), 2065-2073.

556 Ladich, F., Bischof, C., Schleinzer, G., \& Fuchs, A. (1992). Intra-and interspecific differences in 557 agonistic vocalization in croaking gouramis (genus: Trichopsis, Anabantoidei, Teleostei). 558 Bioacoustics, 4(2), 131-141.

559 Ladich, F. (2007). Females whisper briefly during sex: context- and sex-specific differences in 560

Ladich, F. (2018). Acoustic communication in fishes: Temperature plays a role. Fish and Fisheries, 19(4), 598-612.

Ladich, F., and Fine, M. L. (2006). Sound-Generating Mechanisms in Fishes: A Unique Diversity in Vertebrates. Communication in Fishes, 1, 3-43.

Ladich, F., \& Myrberg, A. A. (2006). Agonistic behavior and acoustic communication. Communication in fishes, 1, 121-148.

Ladich, F. and A. Tadler. (1988). Sound production in Polypterus (Osteichthyes: Polypteridae). Copeia 1988: 1076-1077.

Lagardère, J. P., and Mariani, A. (2006). Spawning sounds in meagre Argyrosomus regius recorded in the Gironde estuary, France. Journal of Fish Biology, 69(6), 1697-1708.

Lin, Y. C., Mok, H. K., \& Huang, B. Q. (2007). Sound characteristics of big-snout croaker, Johniusmacrorhynus (Sciaenidae). The Journal of the Acoustical Society of America, 121(1), 586-593.

Luczkovich JJ, Sprague MW, Johnson SE, Pullinger RC (1999) Delimiting spawning areas of weakfish, Cynoscion regalis (family Sciaenidae), in Pamlico Sound, North Carolina using passive hydroacoustic surveys. Bioacoustics, 10, 143-160.

Luczkovich, J. J., Pullinger, R. C., Johnson, S. E., and Sprague, M. W. (2008). Identifying Sciaenid Critical Spawning Habitats by the Use of Passive Acoustics. Transactions of the American Fisheries Society, 137(2), 576-605.

Marôco, J. (2018). Análise Estatística com o SPSS Statistics. 7th Edition. ReportNumber, Pêro Pinheiro, Portugal.

McKibben, J. R. and Bass, A. H. (2001). Effects of temporal envelope modulation on acoustic signal recognition in a vocal fish, the plainfin midshipman. The Journal of the Acoustical Society of America 109, 2934-2943.

Monfort M. C. (2010) Present market situation and prospects of meagre (Argyrosomus regius), as an emerging species in Mediterranean aquaculture. Studies and Reviews, General Fisheries Commission for the Mediterranean No. 89. Roma: FAO

Montie EW, Kehrer C, Yost J, Brenkert K, O’Donnell T, Denson MR. (2016). Long-term monitoring of captive red drum Sciaenops ocellatus reveals that calling incidence and structure correlate with egg deposition. Journal of Fish Biology 88(5):1776-1795

Myrberg Jr, A. A., Ha, S. J., \& Shamblott, M. J. (1993). The sounds of bicolor damselfish 
592

593

594

595

596

597

598

599

600

601

602

603

604

605

606

607

608

609

610

611

612

613

614

615

616

617

618

619

620

621

622

623

624

625

626

627

628

629

630

(Pomacentrus partitus): predictors of body size and a spectral basis for individual recognition and assessment. The Journal of the Acoustical Society of America, 94(6), 3067-3070.

Parmentier, E., Di Iorio, L., Picciulin, M., Malavasi, S., Lagardère, J. P., \& Bertucci, F. (2018). Consistency of spatiotemporal sound features supports the use of passive acoustics for long-term monitoring. Animal conservation, 21(3), 211-220.

Parsons, M. J., McCauley, R. D., Mackie, M. C., Siwabessy, P., and Duncan, A. J. (2009). Localization of individual mulloway (Argyrosomus japonicus) within a spawning aggregation and their behavior throughout a diel spawning period. In ICES Journal of Marine Science, 66,1007-1014.

Parsons, M. J. G., McCauley, R. D., and Mackie, M. C. (2013). Characterisation of mulloway Argyrosomus japonicus advertisement sounds. Acoustics Australia, 4l(3), 196-201.

Radford, A. N., Kerridge, E., \& Simpson, S. D. (2014). Acoustic communication in a noisy world: can fish compete with anthropogenic noise?. Behavioral Ecology, 25(5), 1022-1030.

Rowell, T. J., Demer, D. A., Aburto-Oropeza, O., Cota-Nieto, J. J., Hyde, J. R., and Erisman, B. E. (2017). Estimating fish abundance at spawning aggregations from courtship sound levels. Scientific Reports, 7(1), 3340.

Saucier, M. H. and Baltz, D. M. (1993). Spawning site selection by spotted seatrout, Cynoscion nebulosus, and black drum, Pogonias cromis, in Louisiana. Env. Biol. Fish. 36, 257-272.

Schleinzer, G. (1992) Lautanalysen bei der Gattung Trichopsis (Belontiidae, Teleostei) in Abhängigkeit von Art, Geschlecht und Temperatur. M.S. thesis, Univ. Vienna.

Sprague, M. W., and J. J. Luczkovich. (2001). Do striped cusk-eels Ophidion marginatum (Ophidiidae) produce the "chatter" sound attributed to weakfish Cynoscion regalis (Sciaenidae)? Copeia, 2001(3), 854-859.

Tavolga, W. N. (1964). Sonic characteristics and mechanisms in marine fishes. Marine BioAcoustics, 1, 195-211.

Takemura, a. (1978). Studies on the underwater sound VII: underwater calls of the Japanese Marine drum Fishes (Sciaenidae). Bulletin of the Japanese Society of Scientific Fisheries, 44, 121-125.

Tellechea, J.S., Martinez, C., Fine, M.L., Norbis, W. (2010). Sound production in the whitemouth croaker and relationship between fish size and disturbance call characteristics. Environmental Biology of Fishes, 89, 163-172.

Tellechea, J. S., Norbis, W., Olsson, D., \& Fine, M. L. (2011). Calls of the black drum (Pogonias cromis: Sciaenidae): geographical differences in sound production between northern and southern hemisphere populations. Journal of Experimental Zoology Part A: Ecological Genetics and Physiology, 315(1), 48-55.

Tellechea, J. S., \& Norbis, W. (2012). Sexual dimorphism in sound production and call characteristics in the striped weakfish Cynoscion guatucupa. Zoology Studies, 51, 946-955.

Tellechea, J. S., Fine, M. L., and Norbis, W. (2017). Passive acoustic monitoring, development of disturbance calls and differentiation of disturbance and advertisement in the Argentine 
631 croaker Umbrina canosai (Sciaenidae). Journal of Fish Biology, 90(4), 1631-1643.

632 Tower, R. W. (1908). The production of sound in the drumfishes, the sea-robin and the toadfish. 633 Annals of the New York Academy of Sciences, 18(1), 149-180.

634 Vieira, M., Pereira, B. P., Pousão-Ferreira, P., Fonseca, P. J., \& Amorim, M. (2019). Seasonal 635 Variation of Captive Meagre Acoustic Signalling: A Manual and Automatic Recognition 636 Approach. Fishes, 4(2), 28.

637 Ueng, J. P., Huang, B. Q., and Mok, H. K. (2007). Sexual differences in the spawning sounds of 638 the Japanese croaker Argyrosomus japonicus (sciaenidae). Zoological Studies, 46(1), 103639110.

640 Zar, J. H. (1984). Biostatistical Analysis. Englewood Cliffs, NJ: Prentice-Hall, Inc. 360 
Figure 1

Schematic figure depicting the experimental setup for the assessment of ontogenetic and sex variation of disturbance sounds.

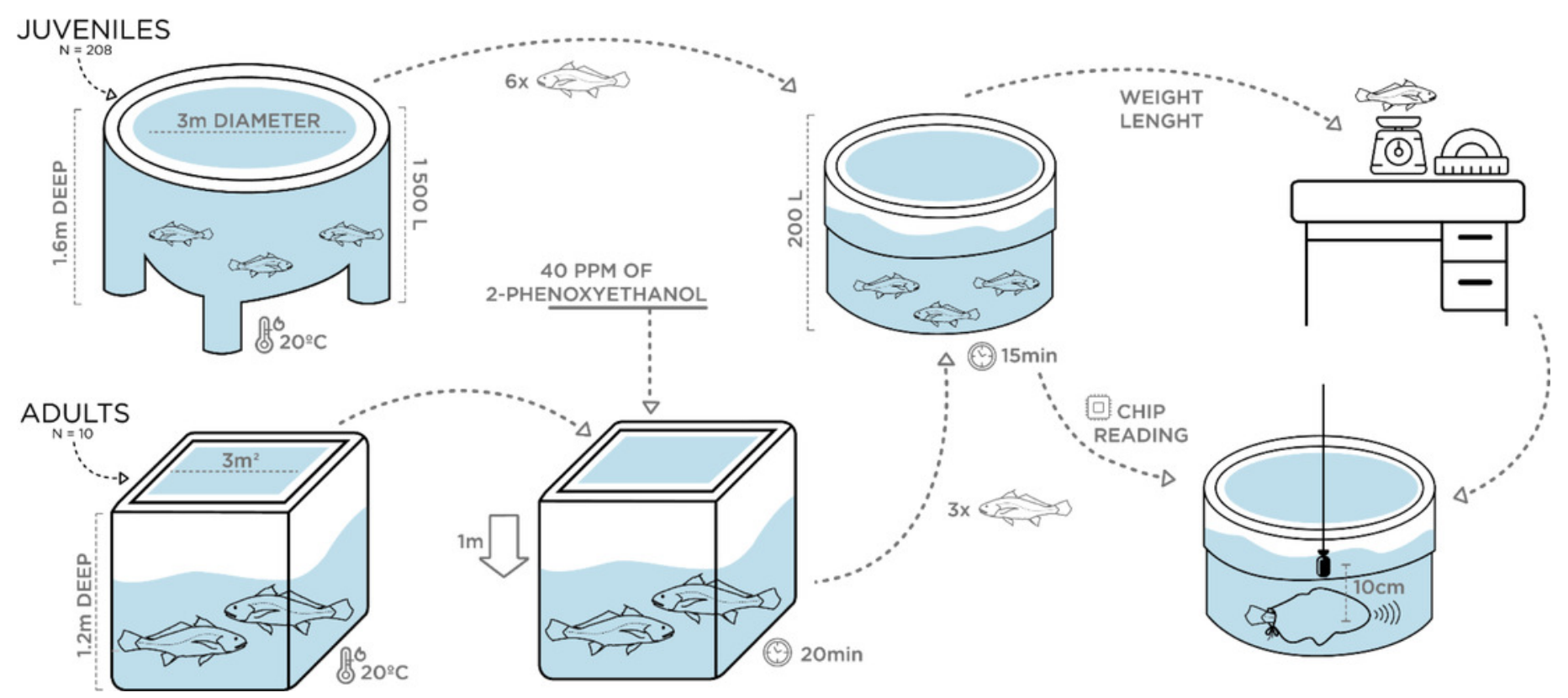




\section{Figure 2}

Oscillograms, spectrograms and power spectra of Argyrosomus regius sounds, representing some of the measured acoustic parameters.

Panels depict oscillograms (and a fragment of the oscillogram), sonograms and power spectra of (A) juvenile meagre's voluntary sound, (B) adult meagre's voluntary sound, (C) voluntary sound recorded in the field during the breeding season, (D) juvenile meagre's disturbance sound, (E) adult meagre's disturbance sound. Pulse period (pp), sound duration (sd), peak frequency (red arrow), Q1 and Q3 frequencies (blue selection; frequency intervals containing $25 \%$ and $75 \%$ of the energy in the spectrum). Spectrum and spectrogram configuration: Sampling frequency, 6 kHz; FFT size, 1024; window points: 96; window type, Hanning; overlap samples per frame, $50 \%$. 
Field

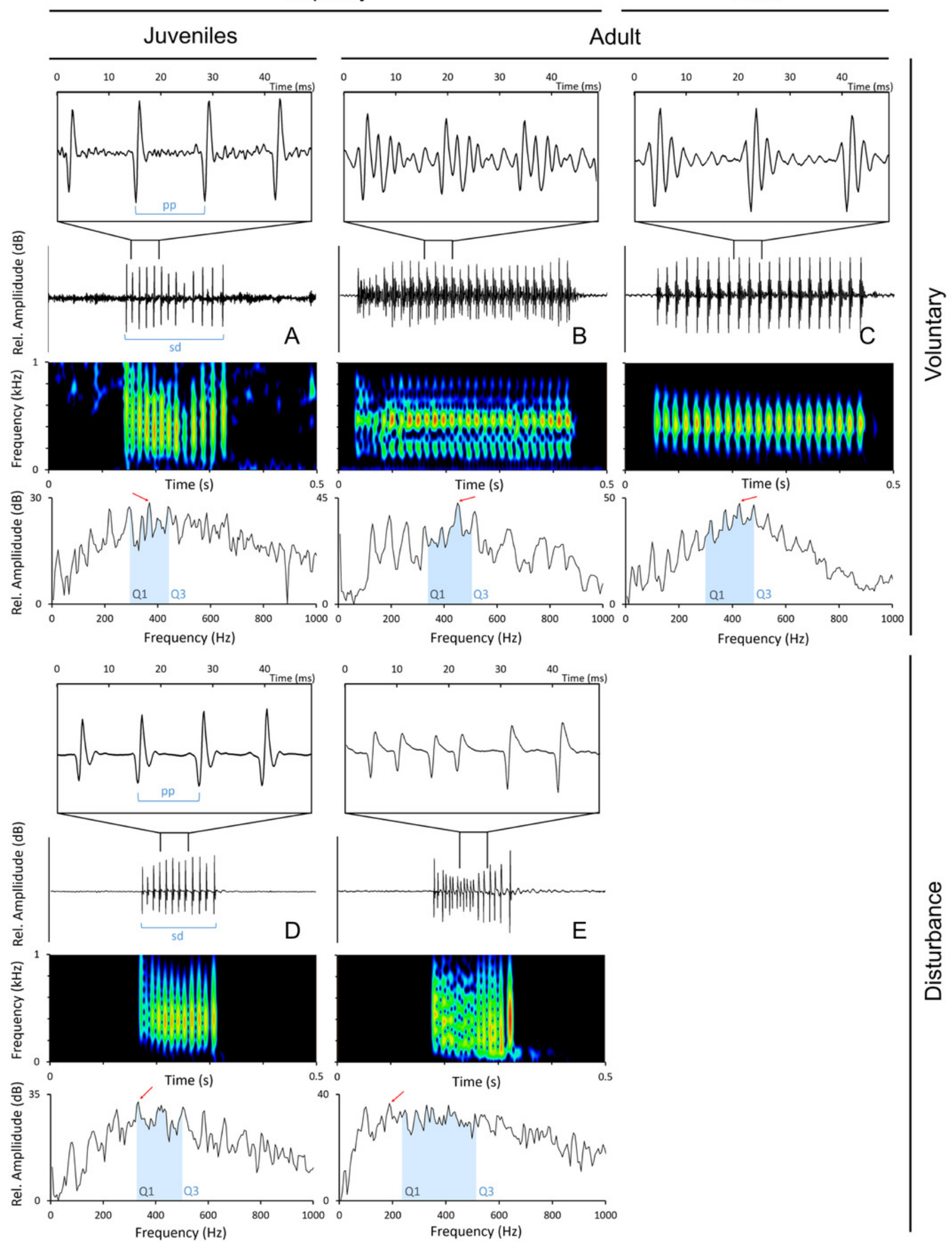




\section{Figure 3}

Dissected juvenile meagre with a total length of ca. $9 \mathrm{~cm}$ depicting the sonic apparatus, lacking the extrinsic sonic muscles.

(A) Photography of juvenile ( $T L=9 \mathrm{~cm}$ ) with open body cavity. (B) Enlargement of the same picture depicting raised body wall (BW), anterior part of the swimbladder (SB) and testicles (T). No distress sounds were registered from juveniles of this size, but distress and social sounds were registered from the remaining studied juvenile fish $(T L>30 \mathrm{~cm})$.

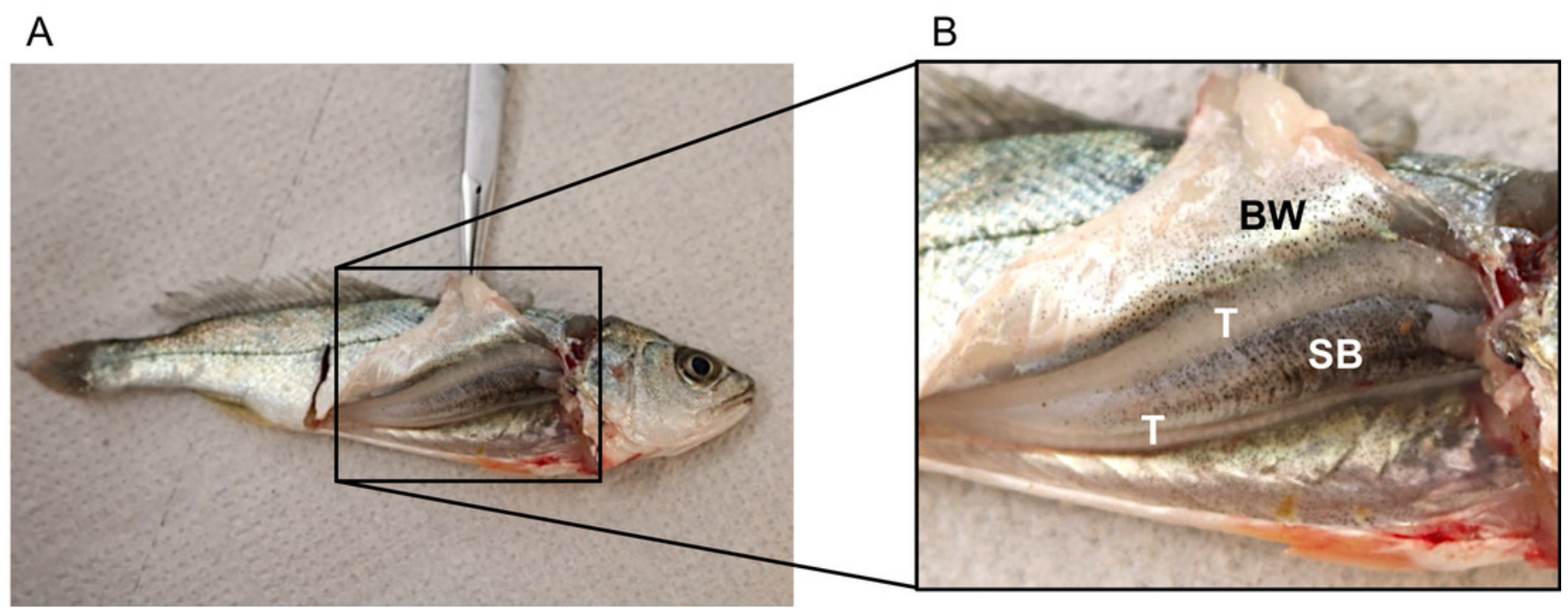


Figure 4

Relation of fish total length to meagre disturbance sounds parameters.

Relation between total length $(\mathrm{cm})$ and $(A)$ sound duration $(\mathrm{ms}),(B)$ number of pulses, $(C)$ pulse period (ms), (D) peak and Q3 frequencies (Hz). Fish ranged from 31 to $102 \mathrm{~cm}$ in total length $(n=30)$ and all recordings were made at $20^{\circ} \mathrm{C}$. Regression lines and $95 \%$ confidence intervals are shown. $r$ and $p$-values are from Pearson correlation tests.
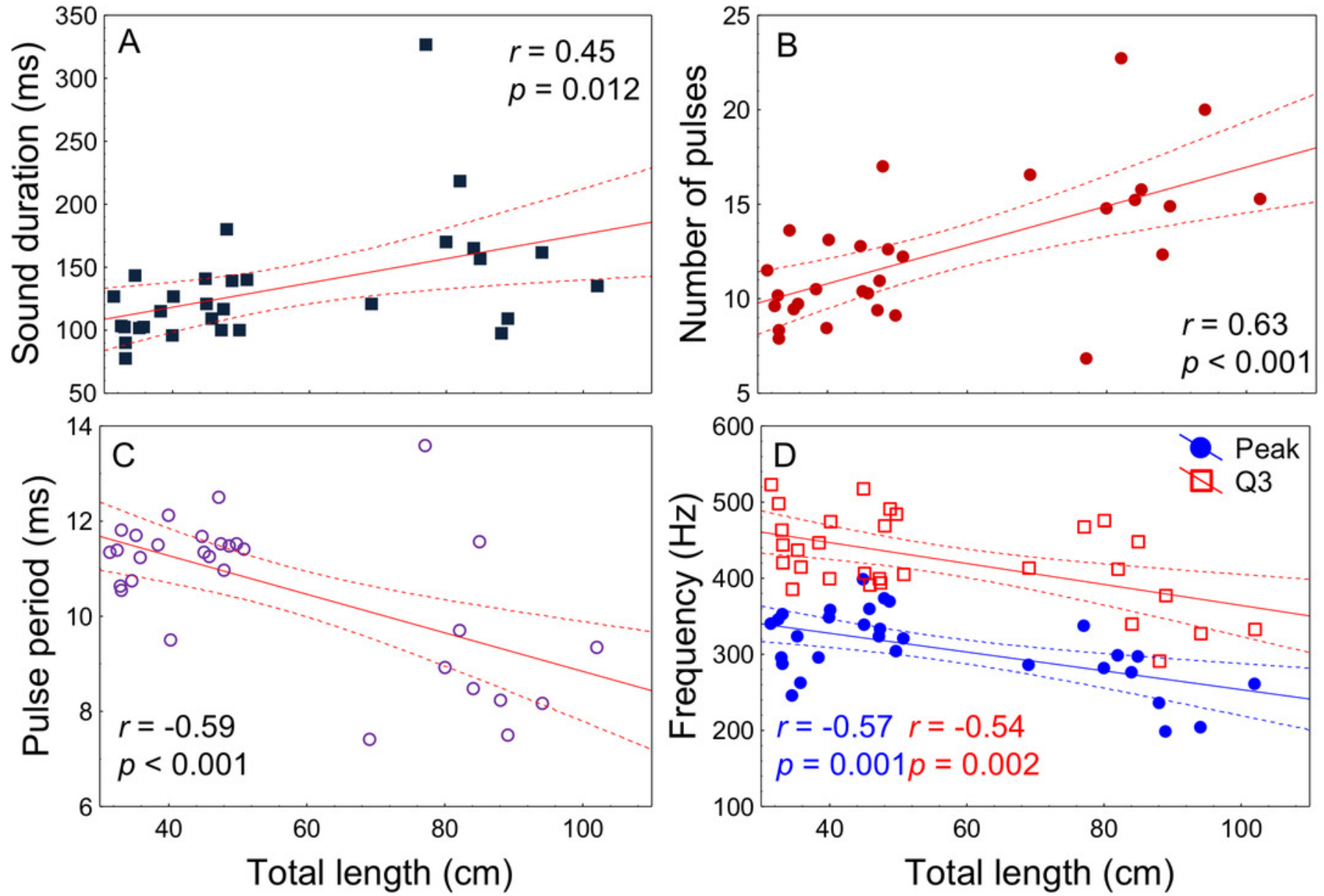


\section{Figure 5}

Comparison of acoustic parameters of sounds emitted by juvenile and adult meagre according to context.

50 sounds were considered per ontogenetic class and context. The boxplots represent medians (central square), the $25^{\text {th }}$ to $75^{\text {th }}$ percentiles (boxes) and $5^{\text {th }}$ and $95^{\text {th }}$ (whiskers) for (A) sound duration (ms), (B) number of pulses, (C) pulse period (ms) and (D) peak frequency $(\mathrm{Hz})$. Raw data is depicted. Different letters denote significant pairwise differences. 

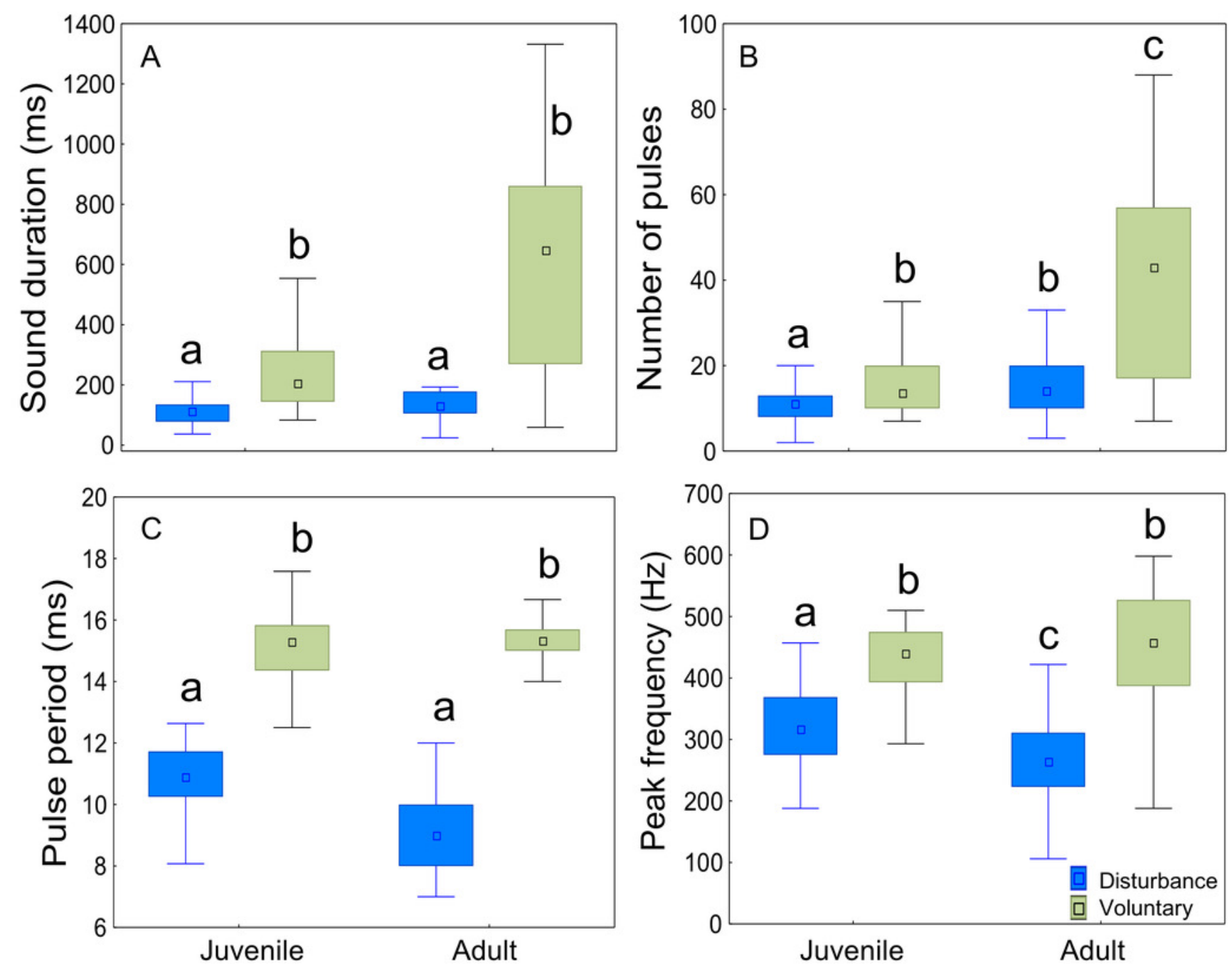

Ontogenetic phase 


\section{Figure 6}

Differences between disturbance and voluntary sounds observed in juveniles and in adults.

(A-F) Variation in sound duration, pulse period and peak frequency with the number of pulses for disturbance and voluntary calls, made by juvenile and adult meager. Scatterplots were performed with 100 voluntary sounds ( 50 sounds per ontogenetic group) and 500 disturbance sounds (200 sounds for 10 adults; 400 sounds for 20 juveniles). 

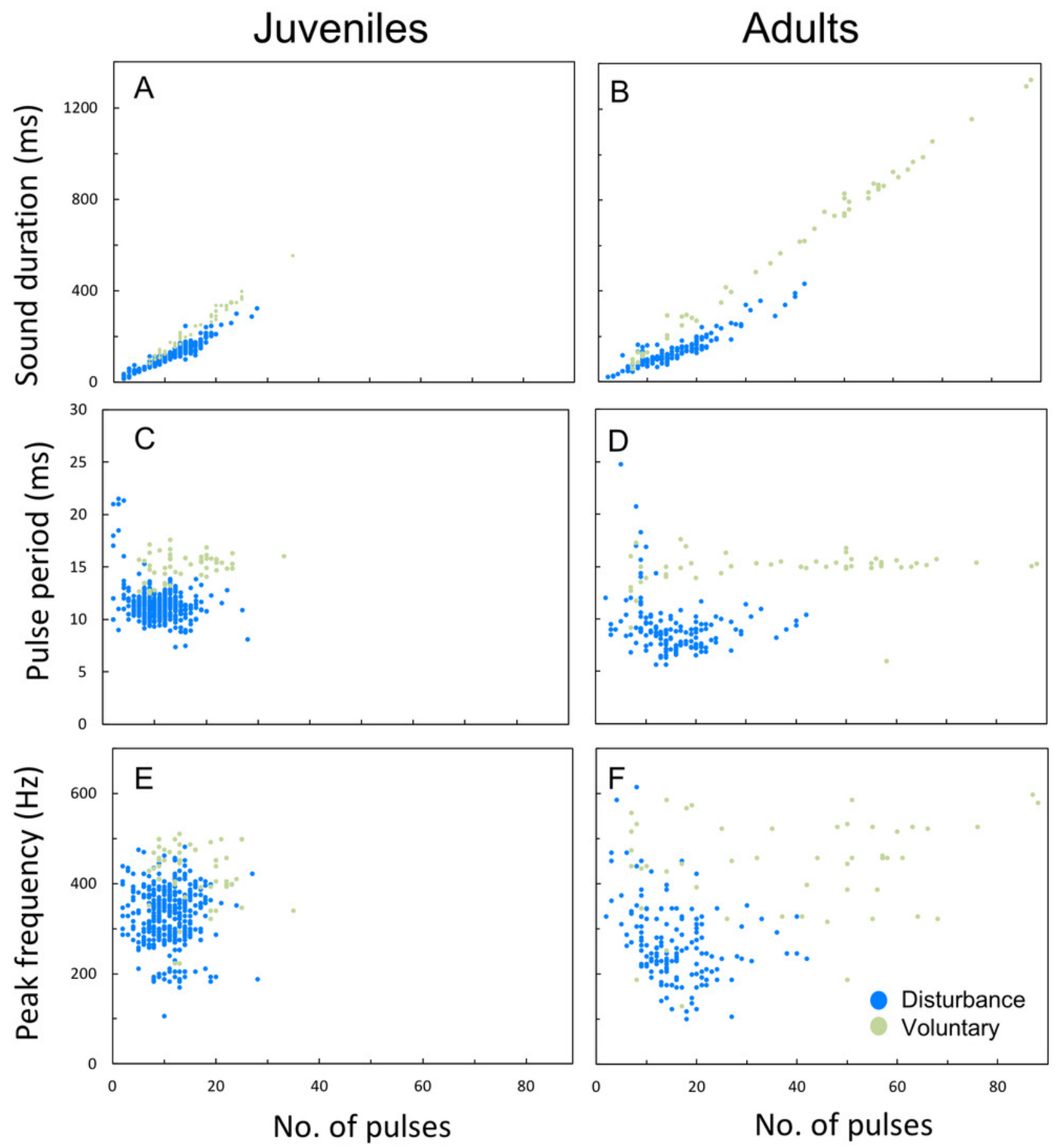


\section{Figure 7}

Comparison of sex-related differences in acoustic parameters of adult meagre's disturbance sounds.

20 sounds per fish ( $n=30$ ) were considered. (A) sound duration (ms), (B) number of pulses,

(C) pulse period (ms) and (D) peak frequency. The boxplots represent medians (central square), the $25^{\text {th }}$ to $75^{\text {th }}$ percentiles (boxes) and $5^{\text {th }}$ and $95^{\text {th }}$ (whiskers). Raw data is depicted. Parameters that are significantly different are indicated by $*$ for $p<0.05$ (Student's $t$-test).
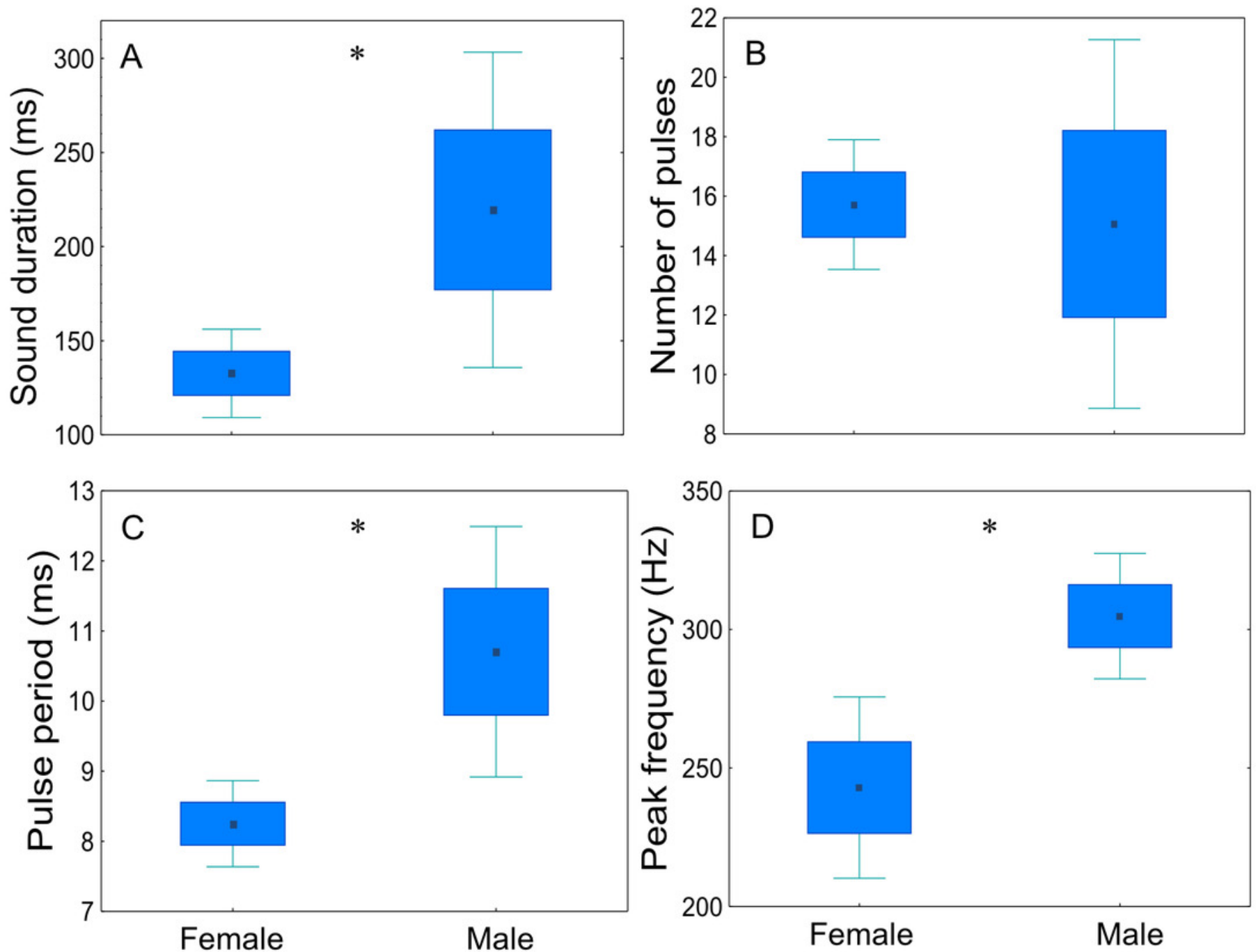
Figure 8

Comparison of acoustic parameters of sounds emitted by meagre in the field and in captivity.

50 sounds were considered for wild individuals and 70 sounds for captive. (A) Sound duration (ms), (B) number of pulses, (C) pulse period (ms) and (D) peak frequency (Hz). The boxplots represent medians (central square), the $25^{\text {th }}$ to $75^{\text {th }}$ percentiles (boxes) and $5^{\text {th }}$ and $95^{\text {th }}$ (whiskers). Raw data is depicted. Parameters that are significantly different are indicated by $* * *$ for $p<0.001$ (ANCOVA).
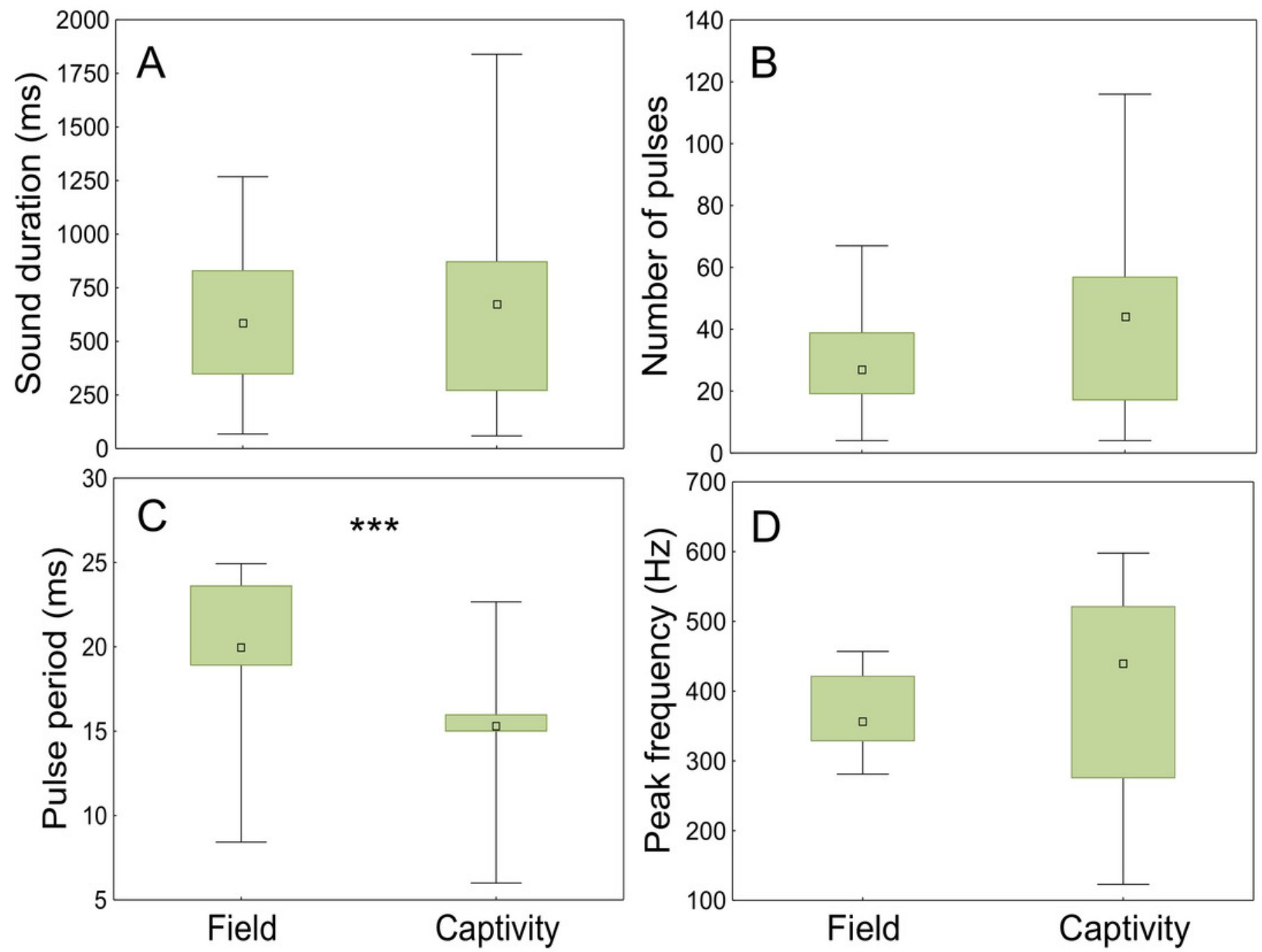


\section{Table $\mathbf{1}$ (on next page)}

Relation between total length $(\mathrm{cm})$ and sound features (Pearson correlation) for juvenile and adult meagre ( $n=30$ fish, 20 sounds per fish). 
1 Table 1. Relation between total length $(\mathrm{cm})$ and sound features (Pearson correlation) for juvenile and adult meagre (n $2=30$ fish, 20 sounds per fish).

\begin{tabular}{lcc}
\hline Sound features & $r$ & p-value \\
\hline Sound duration (ms) & 0.45 & 0.012 \\
Number of pulses & 0.63 & $<0.001$ \\
Pulse period (ms) & -0.59 & $<0.001$ \\
Peak frequency (Hz) & -0.57 & 0.001 \\
Q1 frequency (Hz) & -0.14 & 0.43 \\
Q3 frequency (Hz) & -0.54 & 0.002 \\
\hline
\end{tabular}

3

4 


\section{Table 2 (on next page)}

Effects of context and ontogenetic phase on sound features.

Results refer to parametric two-way ANOVAs in the case of sound duration, number of pulses and pulse period following data transformations and to the equivalent non-parametric test for peak frequency. 50 sounds were considered per ontogenetic class and context (see Methods for details). 
1 Table 2. Effects of context and ontogenetic phase on sound features. Results refer to parametric two-way ANOVAs in the case of sound duration, number of pulses and pulse period following data transformations and to the equivalent non-parametric test for peak frequency. 50 sounds were considered per ontogenetic class and context (see Methods for details).

\begin{tabular}{lcccccccccccccc}
\hline & \multicolumn{3}{c}{ Sound duration (ms) } & \multicolumn{3}{c}{ Number of pulses } & \multicolumn{3}{c}{ Pulse period (ms) } & \multicolumn{3}{c}{ Peak frequency (Hz) } \\
\cline { 2 - 13 } Factors & $\mathrm{df}$ & $\mathrm{F}$ & $p$-value & $\mathrm{df}$ & $\mathrm{F}$ & $p$-value & $\mathrm{df}$ & $\mathrm{F}$ & $p$-value & $\mathrm{df}$ & $\mathrm{H}$ & $p$-value \\
\hline Context & 1,194 & 61.08 & $<0.001$ & 1,189 & 21.21 & $<0.001$ & 1,189 & 155.51 & $<0.001$ & 1 & 83.21 & $<0.001$ \\
\hline Ontogenetic phase & 1,194 & 9.62 & 0.002 & 1,189 & 18.16 & $<0.001$ & 1,189 & 0.67 & 0.41 & 1 & 1.45 & 0.23 \\
\hline Interaction & 1,194 & 0.02 & 0.88 & 1,189 & 0.19 & 0.67 & 1,189 & 3.35 & 0.07 & 1 & 3.50 & 0.06 \\
\hline
\end{tabular}

5 


\section{Table 3 (on next page)}

Sound duration, number of pulses, pulse period and peak frequency of sounds produced by meagre per ontogenetic group, sex and context. 
2 Table 3. Sound duration, number of pulses, pulse period and peak frequency of sounds produced by meagre per ontogenetic group, sex and context.

\begin{tabular}{|c|c|c|c|c|c|c|c|c|c|c|c|}
\hline & & & \multicolumn{2}{|c|}{ Sound duration (ms) } & \multicolumn{2}{|c|}{ Number of pulses } & \multicolumn{2}{|c|}{ Pulse period (ms) } & \multicolumn{2}{|c|}{ Peak frequency $(\mathrm{Hz})$} & \multirow[b]{2}{*}{$\mathrm{n}$} \\
\hline & & & Mean \pm SD & Range & Mean \pm SD & Range & Mean \pm SD & Range & Mean \pm SD & Range & \\
\hline \multicolumn{12}{|l|}{ Disturbance } \\
\hline & Adults & Female $(n=6)$ & $133 \pm 29$ & $97-170$ & $16 \pm 3$ & $12-21$ & $8 \pm 1$ & $7-9$ & $243 \pm 41$ & $192-286$ & 120 \\
\hline & & Male $(n=4)$ & $220 \pm 85$ & $156-341$ & $15 \pm 6$ & $7-22$ & $11 \pm 2$ & $8-13$ & $305 \pm 23$ & $276-329$ & 80 \\
\hline & Juveniles & $(\mathbf{n}=\mathbf{2 0})$ & $117 \pm 46$ & $15-322$ & $11 \pm 4$ & $2-28$ & $11 \pm 2$ & $7-22$ & $329 \pm 63$ & $106-481$ & 400 \\
\hline \multicolumn{12}{|l|}{ Voluntary } \\
\hline & Adults & Captivity & $626 \pm 407$ & $59-1839$ & $40 \pm 23$ & $4-116$ & $16 \pm 2$ & $6-22$ & $384 \pm 110$ & $123-598$ & 70 \\
\hline & & Field & $574 \pm 304$ & $68-1268$ & $28 \pm 14$ & $4-67$ & $21 \pm 3$ & $8-25$ & $363 \pm 50$ & $281-457$ & 50 \\
\hline & Juveniles & & $231 \pm 101$ & $83-554$ & $16 \pm 6$ & $7-35$ & $15 \pm 1$ & $13-18$ & $424 \pm 68$ & $223-510$ & 50 \\
\hline
\end{tabular}

